\title{
Application of Lean Thinking in Reducing Turn Around Time on the Quality Control Process at Nickel Processing Plant
}

\author{
Pendra Sagita, and Moses Laksono Singgih \\ Department of Industrial and System Engineering, Institut Teknologi Sepuluh Nopember, Surabaya \\ e-mail:pensagita@gmail.com
}

\begin{abstract}
Abstrak-This work presents a case study focused on reducing the turn around time in the quality control process at Nickel processing plant, using Lean Thinking tools. The Nickel industry, the process is drying, reducting, smelting, and converting. This process needs to be controlled to get the optimal result, and the process needs to be controlled quickly. So the analysis data must be generated in a short time. They are recording time and activities from sampling until reporting the data carried out to analyze the current situation using value stream mapping to identify the main problem, such as high waiting times. The root cause of the main problem is sought by using the fishbone diagram and given an improvement suggestion according to the origins of the problem. The application of these improvements can reduce the analysis time in the quality control process by $\mathbf{9 8 . 5 2 \%}$ of the total cycle time.
\end{abstract}

Kata Kunci-Fishbone Diagram, Lean Thinking, Value Stream Mapping.

\section{INTRODUCTION}

$\mathrm{N}$ ICKEL processing operations are divided into several processes. These processes include the drying process at dryer kiln, nickel ore reduction ar reduction kiln, melting process at the electric furnace, and finally purification process at the converter. The implementation of the production process at all stages has chemical parameters that must be carried out with reasonable quality control. The purposes of the quality control are to maintain concentrations of metal elements must be on specification, to keep the wasted nickel is intolerance limit, and to maintain the concentration of some elements (Silica, Magnesia, Iron, and Cobalt).

The chemical parameter was generated in the laboratory. The laboratory conduct sample testing to obtain elements data. The testing process begins from sampling, sample preparation, and sample analysis to get elements data. The process to produce the data requires a high turn around time, while to do quality control on the production process, the data must be generated in a fast time. The time that the laboratory currently gives compared with the required time can be seen on the graph Figure 1.

The graph Figure 1 shows that the data produced by the laboratory requires a longer time than the time needed to control the quality of the production process. Based on these problems, it is necessary to do a case study on reducing turn around time in the quality control process using lean thinking principle. This case study is carried out by describing the current state using Value Stream Mapping (VSM), then waste identified with the process activity mapping, identified the root cause of waste, and purpose the improvement using a fishbone diagram. Furthermore, future state mapping is described using VSM, and then compared between the current state and future state mapping.

\section{METHODOLOGY}

The application of lean thinking in reducing turn around time on the quality control process at the Nickel processing plant consists of several research stages. This case study conducted to reduce turn around time on quality control. The first stage is to describe the current state using value stream mapping, the second stage is identified waste activity using process activity mapping. The third stage is to the identified root cause of waste using a fishbone diagram. The fourth stage is the purpose of the improvement idea. Ultimately, the future state is created, and this shows the result of turn around time reduction in the case study, as well as the saving costs resulting from the reduction time and simplify the analysis process in the laboratory.

\section{RESULT}

\section{A. Current State Value Stream Mapping}

VSM is a process flow map of the company and all related matters therein. Figure 2 shows a picture of the current state value stream mapping that illustrates the initial conditions of the process. There are two types of grooves in the nickel processing plant that is information flow and physical flow. The flow of information related to several divisions that cause communication processes, for example, with procurement, and customers. While the physical flow is related to the sample preparation process in the sample house division, and sample analysis in the laboratory division.

Based on the current state value stream mapping, there is two long processes that is sample preparation in the sample house and sample analysis in the laboratory. In each process, there is processing time, and the number of operators needed, so that takt time value is taken from each method. Based on the physical flow and information flow and information flow on the value stream mapping that has been made, it can be identified the problems occur in the process on analyzing samples on quality control of production in Nickel processing plants, that is:

1. Sampling from a location far enough away from the place of preparation takes a considerable amount of time. Transportation is an activity that does not provide added 
The $6^{\text {th }}$ International Seminar on Science and Technology (ISST) 2020

July $25^{\text {th }} 2020$, Institut Teknologi Sepuluh Nopember, Surabaya, Indonesia

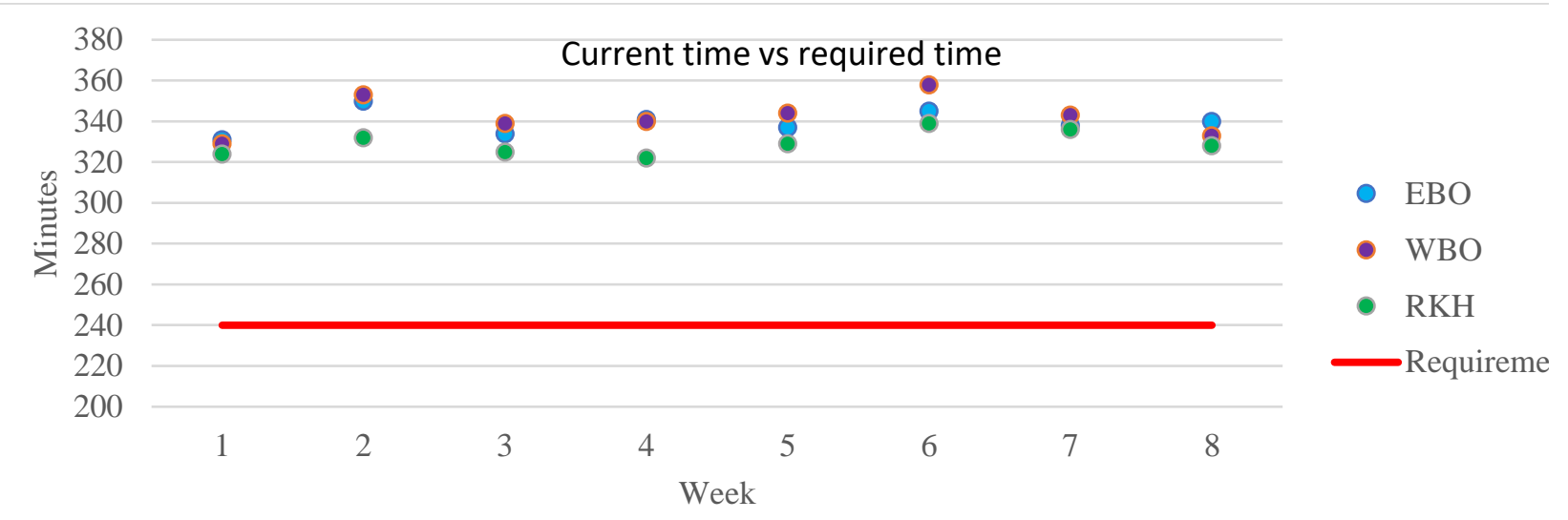

Figure 1. Current turn around time compared to the required time.

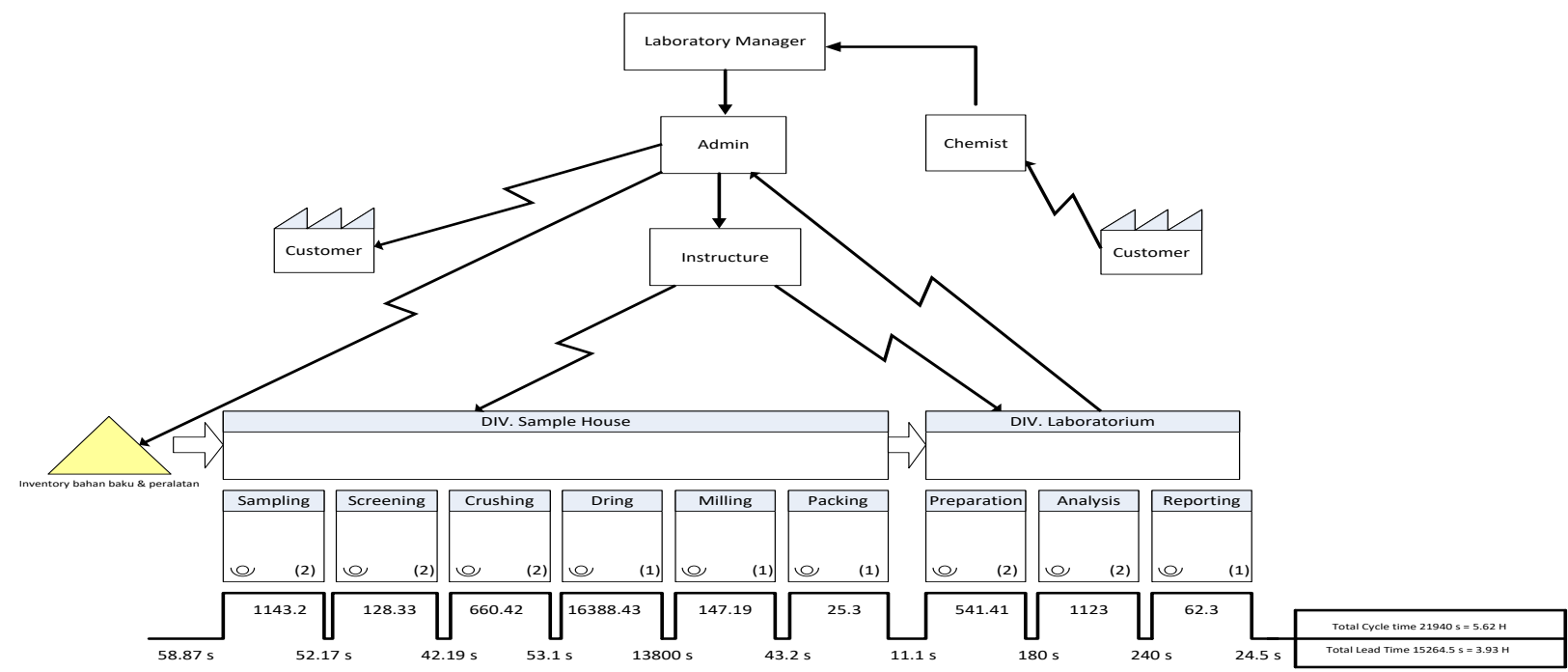

Figure 2. Current state value stream mapping on the sample analysis process.

value (Non-Value Added). Also, the sampling point is located at a plant. The conditions are often unsafe to carry out, and hazardous conditions hamper the sampling activity.

2. The whole process shows that there is still a process that is not valuable and indeed must be carried out, such as the sample drying process and the process of melting the sample, causing the waiting time.

3. The process of inputting data that is still done manually by workers is often missed, thereby increasing the duration of the process.

Based on the problems found above, it is necessary to analyze in more detail the waste that occurs in the analysis of the quality control of the production process.

\section{B. Process Activity Mapping}

Making the process activity mapping requires direct observation of the process, activities of each process, distance, time, and labor involved. The result is input to a table where each activity will be grouped into five types of activities, namely operations, transportation, inspection, delay, and storage. From this table, we get the proportion of the number of activities and the time of each type of activity. With the understanding that value-added activities are activities that provide added value and cannot be eliminated. Non-value added activity is an activity that has no added value and can be eliminated. In contrast, necessary nonvalue-added activity is an activity that is still needed in the process but does not provide added value to the product. Amount and proportion of time for each activity shown in the table 1.

Based on the table 1, it can be seen that in the process of analyzing sample, the proportion of the time delay (waiting) takes the most time is in the amount of 16775.94 seconds or equivalent to $82.97 \%$ of the total time. Next is the operation $(11.86 \%)$, transportation $(3.75 \%)$, storage $(1.11 \%)$ and the last is inspection $(0.31 \%)$. Here is the calculation of the Value added ratio:

$$
\begin{aligned}
& \text { Value added ratio } \\
& =\frac{\text { value added time (process time) }}{\text { total process cycle time }} \times 100 \% \\
& =\frac{1185.3}{20220} \times 100 \%=\mathbf{5 . 8 6} \%
\end{aligned}
$$


The $6^{\text {th }}$ International Seminar on Science and Technology (ISST) 2020

July $25^{\text {th }} 2020$, Institut Teknologi Sepuluh Nopember, Surabaya, Indonesia

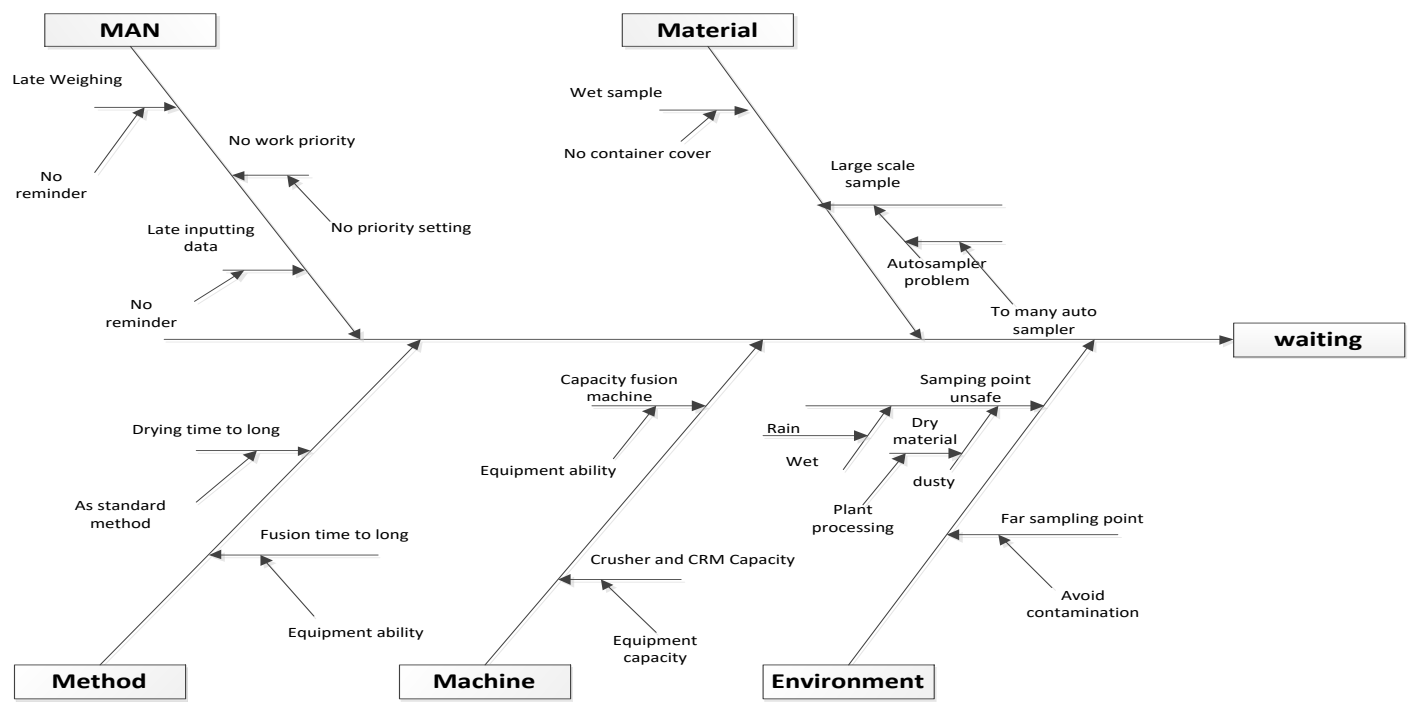

Figure 3. Root cause identification by fishbone diagram.

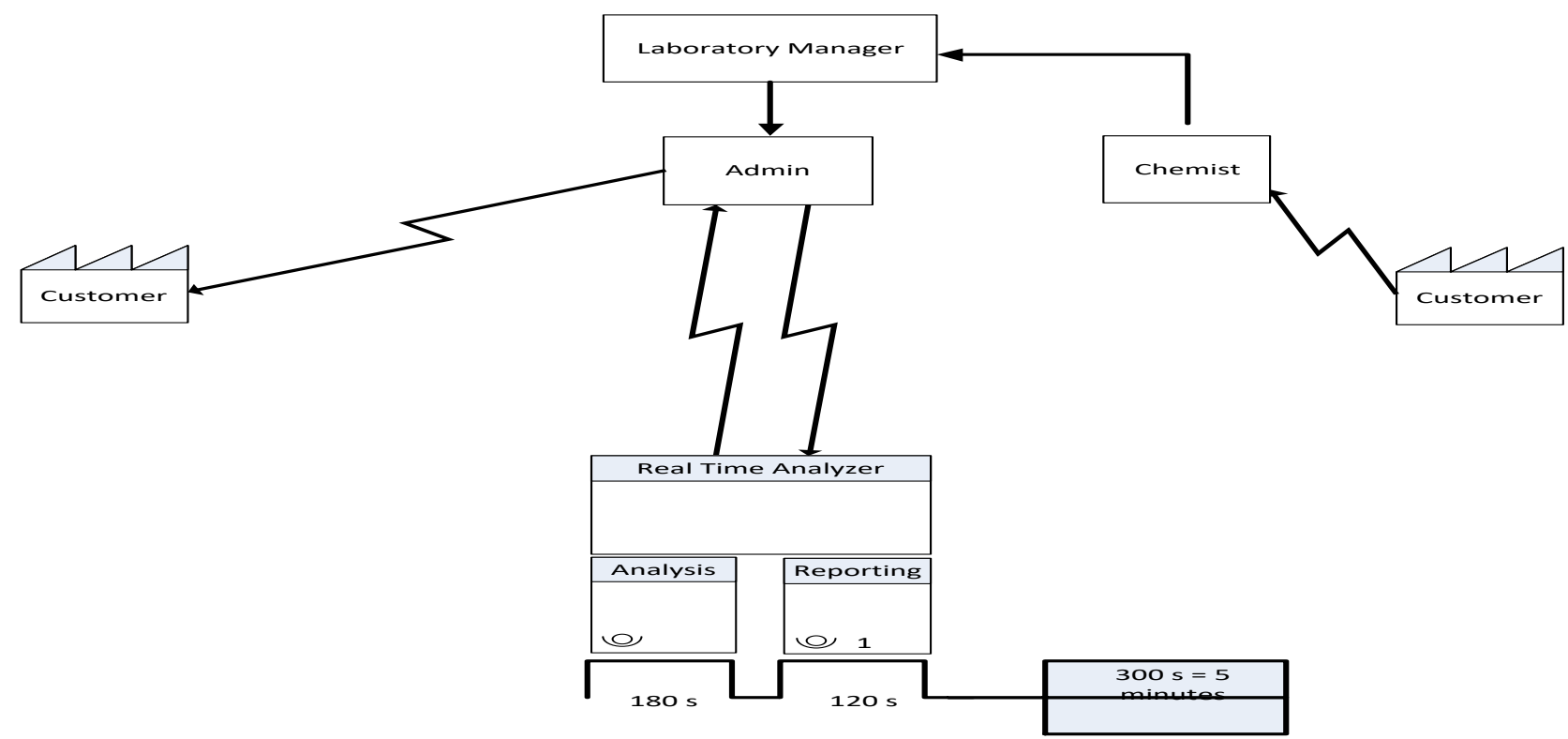

Figure 4. Future state value stream mapping.

Based on the calculation above it can be concluded that the activities that have added value are only $5.86 \%$ of the total time needed. In comparison, the Non Value Added activities take the proportion of time by $94.14 \%$, and $88.13 \%$ of them are waiting for activities, while activities that are necessary non-value added with a portion of $0.31 \%$. This shows that most of the process of analyzing the test sample is currently an activity that does not provide added value and must be replaced with activities that can provide added value. Continuous improvement is not just about removing nonvalue-added but also about how to replace the non-value added activities with value-added activities.

\section{Identify the Root Cause with the Fishbone Diagram}

This fishbone diagram will identify the causes of waste based on the results of the waste analysis, that is delay (waiting), this diagram is obtained from brainstorming results with several experienced employees who are experts in their fields, such as group leaders, and senior employees. The fishbone diagram can be seen in the Figure 3 .
Based on the results of the analysis, using a fishbone diagram can be seen as a variety of causes that exist. These causes are classified into five categories, namely Man, Material, Measurement, Method, Machine, and Environment. Each category has several causes, which are as follows:

\section{1) Man}

Man category related to the behavior of workers such as late inputting data, late doing weighing, and not being able to determine work priorities, this is undoubtedly very influential when analyzing test samples.

\section{2) Material}

Material category related to the condition of the test sample which is wet due to imperfect container so that when it rains the test sample is wet and makes it difficult to do the sample preparation

\section{3) Method}

The Method category is related to the method used in the preparation of the test sample requiring an extended drying 
The $6^{\text {th }}$ International Seminar on Science and Technology (ISST) 2020

July $25^{\text {th }} 2020$, Institut Teknologi Sepuluh Nopember, Surabaya, Indonesia

Table 1.

Amount and proportion time for each activity

\begin{tabular}{|c|c|c|c|c|c|c|}
\hline Activity & Amount & Time (s) & Percentage & VA & $\begin{array}{l}\text { NNVA } \\
\end{array}$ & 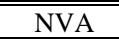 \\
\hline Operation & 19 & 2398.54 & $11.86 \%$ & 1123 & & 1275.54 \\
\hline Transportation & 6 & 759.17 & $3.75 \%$ & & & 759.17 \\
\hline Inspection & 1 & 62.3 & $0.31 \%$ & & 62.3 & \\
\hline Storage & 5 & 224.05 & $1.11 \%$ & & & 224.05 \\
\hline Delay & 2 & 16775.94 & $82.97 \%$ & & & 16775.94 \\
\hline Total & 33 & 20220 & $100.00 \%$ & 1123 & 62.3 & 19034.7 \\
\hline
\end{tabular}

Table 2.

Amount and proportion time for each activity

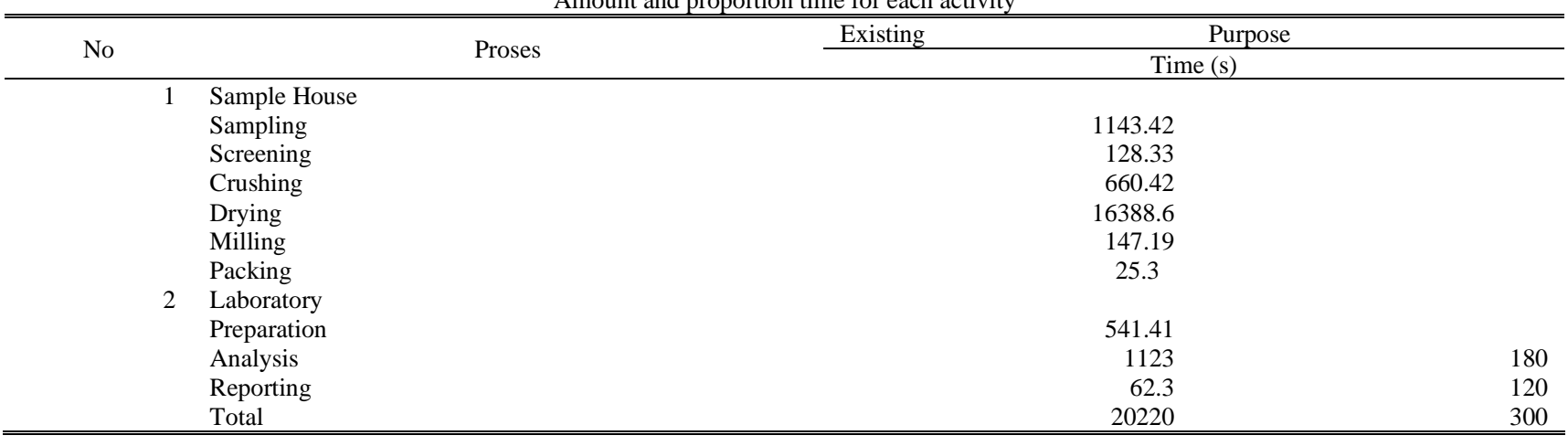

Table 3.

Assumption of cost-saving in production

\begin{tabular}{|c|c|c|}
\hline Saving Cost Assumption & Amount & Unit \\
\hline Furnace Delay in EF3 and EF4 & 19302 & MWH \\
\hline Nickel grade in calcine $(\mathrm{Ni})$ & 1.98 & $\%$ \\
\hline Recovery & 89.6 & $\%$ \\
\hline GHE & 0.456 & \\
\hline LME & 9.3 & $\mathrm{k} \$$ \\
\hline Total Loss due to poor chemistry in EF3 \& EF4 & 6,984 & $\mathrm{k} \$$ \\
\hline Coefficient of savin cost from loss production may be admitted & 30 & $\%$ \\
\hline Saving Cost & $2,095.15$ & $\mathbf{k \$}$ \\
\hline
\end{tabular}

time, and also a long time of fusion, where the activity is only waiting activity.

\section{4) Machine}

The Machine category is related to machines used, such as crushers to destroy test samples, and Continuous Ring Mill used to refine test samples having a small capacity. In contrast, the test samples worked are plentiful in addition to the number of autosamplers, which makes it difficult for the maintenance team to make repairs, so auto the sampler is often in bad condition.

\section{5) Environment}

The environmental category also contributes due to environmental conditions of unsafe test sampling, dangerous conditions triggered by bad weather, and abnormal factory operating conditions. As a company that prioritizes safety, unsafe conditions make work stop. Also, the distance of the autosampler is far from the laboratory location, which causes waiting time.

Based on the results of the analysis of several categories above, there are many contributions to the waiting time, which causes a lengthy analysis process. This condition also illustrates that the process of analyzing test samples is still manual and highly dependent on the worker.

\section{Analysis of Improvement}

The causes of waste that exist in the sample analysis process in controlling the quality of products have been identified so that improvements can be proposed so that the origins of waste can be eliminated. Following are the proposed improvements for the test sample analysis process:

\section{1) Installation of Real-Time Analyzer( Online Analyzer)}

The causes of waste from the analysis using fishbone diagrams illustrate that the sample analysis process is still very dependent on various factors, including humans. Thus, it is necessary to improve the entire process. The improvement is in the form of replacing a manual process into an automatic process. An automated process can eliminate non-value-added activities and shorten the analysis time. The automation process can be realized by installing a real-time analyzer. A real-time analyzer is installed in the processing plant at the sampling location. The working principle of this tool is to illuminate the material in the conveyor belt with a radiation beam at a certain intensity so that it can produce metal content data quickly. Installation of a real time analyzer is expected to provide many benefits, including:

1. Improve sample analysis procedures in the production quality control process so that waste can be eliminated

2. Reducing the sample analysis time in the production quality control process at the processing plant, the total initial analysis time was 337 minutes (5.6 hours) to 5 minutes or a decrease of $98.52 \%$ of the total analysis time. 
The $6^{\text {th }}$ International Seminar on Science and Technology (ISST) 2020

July $25^{\text {th }} 2020$, Institut Teknologi Sepuluh Nopember, Surabaya, Indonesia

Table 4.

Assumption of cost-saving on workforce costs

\begin{tabular}{|c|c|c|c|c|c|}
\hline No. & Identity & Amount & frequency (days) & Price (\$/days) & total $(\$)$ \\
\hline 1 & man power & 3 & 1095 & 40 & 131,400 \\
\hline \multicolumn{6}{|c|}{$\begin{array}{l}\text { Table } 5 \text {. } \\
\text { Assumption cost saving for chemicals }\end{array}$} \\
\hline No. & Identity & & Consumption/Years (kg) & Unit Price (\$) & Total Price \\
\hline 1 & Litium Tetra Borat & & 136.704 & 110 & $15,037.44$ \\
\hline
\end{tabular}

Table 6.

Future State Process Activity Mapping

\begin{tabular}{|c|c|c|c|c|c|c|c|c|c|c|c|}
\hline \multirow{2}{*}{ No. } & \multirow{2}{*}{ Activity } & \multirow{2}{*}{ Machine/tools } & \multirow{2}{*}{ Distance } & \multirow{2}{*}{ Time (s) } & \multirow{2}{*}{$\begin{array}{l}\text { Man } \\
\text { Power }\end{array}$} & \multicolumn{5}{|c|}{ Activity } & \multirow{2}{*}{ NA/NVA/NNVA } \\
\hline & & & & & & $\mathrm{O}$ & $\mathrm{T}$ & I & S & $\mathrm{D}$ & \\
\hline 1 & Analysis & $\begin{array}{l}\text { real time } \\
\text { analyzer }\end{array}$ & & 180.00 & 0 & $X$ & & & & & VA \\
\hline 2 & Reporting & computer & & 120.00 & 1 & & & $\mathrm{X}$ & & & NNVA \\
\hline
\end{tabular}

A comparison of the time of the initial analysis compared to the submission assumption is presented in Table 2.

3. Improve quality control of production at the Nickel processing plant because metal content data can be obtained faster (fast action). To save on production costs as presented in Table 3.

4. Reducing the number of workers in the sample house division, because the equipment is no longer operated by workers. So that it can save costs incurred for man power, the assumption of saving on workforce costs can be seen in Table 4.

5. We are reducing the use of chemicals in the laboratory, to save costs. To save costs incurred for the purchase of chemicals. The assumption of cost savings for purchasing chemicals can be seen in Table 5 .

6. Based on the assumption that the profit will be obtained. Then the Net Present Value (NPV), Internal Rate Return (IRR), and Payback Periode can be calculated from the purposes real-time analyzer. Based on the calculations, NPV values of $\$ 10,516,000$ can be obtained, IRR of $224.5 \%$, and a payback period of 0.45 years for an investment of real-time analyzer $(\$ 759,000)$ in 10 years.

\section{E. Future State Current State Mapping}

After describing the current state mapping and identification of waste, it can be seen that the process needs to be improved so that the conditions of the sample analysis process on production quality control can approach the concept of lean manufacturing by changing the process, from the process manual to the process automation using a real time analyzer. The proposed improvement can be seen from the future state value stream mapping in Figure 4.

Based on the future state value stream mapping, it can be seen that almost the whole process has changed. Waste that has been found has been eliminated, so the process becomes simpler but has added value with the entire processing time of 5 minutes. Proof that the above proposal can reduce the waste that exists in the process of analyzing test samples in controlling production quality can be seen in the process activity mapping (PAM) under the proposed conditions, where the amount of time needed to analyze the test sample is faster than in the current state value stream mapping. The PAM table can be seen in the following table 6 .

Based on PAM table 6, it can be seen that there has been some reduction in the process of analyzing the sample, if compared to the PAM data before improvement there are 33 steps in analyzing the sample, and in the PAM after the purposed improvement there are only two steps in the process. This is due to the loss of operations in the non valueadded activity.

\section{CONCLUSION}

This case study focus on the application of lean thinking in reducing turn around time on the quality control process at Nickel processing plant. This case study conducted to reduce turn around time on the quality control. In the first stage the current state value stream mapping has been conducted, it is found that the types of waste are transportation and waiting. In the second stage identify waste activity using process activity mapping has been conducted, the largest percentage of waste is activity delay (waiting) by $82.97 \%$ and transportation by $3.75 \%$. The value added ratio is $5.86 \%$, with the percentage of non value added activities of $94.14 \%$, and percentage of necessary non value added activities of $0.31 \%$.

The third stage to identified root cause of waste has been done using a fishbone diagram. Based on the results of the analysis of several categories, it contributes a lot to the waiting time which causes along analysis process. This condition also illustrates that the main problem of samples analyzing process is the procedure still manual and highly dependent on the worker. The fourth stage is purpose the improvement idea has conducted. The result of the improvement plan analysis is the installation of a real time analyzer which will replace the manual process into an automated process. The installation of real time analyzer has many advantages based on financial evaluation resulting in a NPV of $\$ 10,516,000$. IRR of $224.5 \%$, and payback period 0.45 years. In addition, the installation of a real time analyzer can reduce $98.52 \%$ turn around time. Based on the comparison of current state and future state, it can be seen that there has been a reduction in the steps in the analysis of 
The $6^{\text {th }}$ International Seminar on Science and Technology (ISST) 2020

July $25^{\text {th }} 2020$, Institut Teknologi Sepuluh Nopember, Surabaya, Indonesia

sample, compared to the data before improvement there are 33 steps in analyzing the samples, and in the data after the purposed improvement there are only 2 steps in the process. That is because the loss of processes in the category on non value added activity.

\section{REFERENCES}

[1] Ayverdi, L., Nakiboglu, C., Oz Aydin, S. (2014). Usage of Graphic Organizers in Science and Tecnology Lessons. Procedia - Social and Behavioral Sciences 116 (2014) 4264 - 4269.

[2] Coccia, M. (2017). The Fishbone Diagram to Identify, Systematize and Analyze the Sources of General Purpose Technologies. Social and Administrative Sciences.

[3] Crosby, P. B. (1979). Quality is Free. McGraw-Hill, New York.

[4] Gaspersz, V., \& Fontana, A. (2011). Lean Six Sigma for Manufacturing and Service Industries. Vinchristo Publication.

[5] Garvin, D. A. (1984). "What Does Product Quality Really Mean?". Sloan Management Review, 26 (1): 25-43.

[6] Juran, J. M., Ed. (1974). Quality Control Handbook $3^{\text {rd }}$ ed. McGrawHill, New York.
[7] KaczMarek, M. J., Saniuk, A. (2018). How to Make Maintenance Processes More Efficient Using Lean Tools?. Springer International Publishing.

[8] Konieczka, P., Namiesnik, J. (2018). Quality Assurance and Quality Control in the Analytical Chemical Laboratory $2^{\text {nd }} e d$. CRC Press, New York.

[9] Mitra, A. (2016). Fundamentals of Quality Control and Improvement $4^{\text {th }} e d$. John Wiley \& Sons, New Jersey.

[10] Nash, M. A., Poling, S. R. (2008). Mapping the Total Value Stream. CRC Prss, New York.

[11] Schaffelke, B., Fabricius, K., Kroon, F., Brodie, J., De'ath, G., Shaw, G., Tarte, D., Warne, M., Thorburn, P. (2018). Support for Improved Quality Control but Misplaced Criticism of GBR Science. Marine Pollution Bulletin.

[12] Shah, R and Ward, P. T. (2003). "Lean Manufacturing: Context, Practices Bundles and Performance". Journal of Operations Management 21 (2), 129-149.

[13] Waszkowski, R., Nowicki, T., Saniuk, A. (2016). Human-computer Interaction in Sanitary Inspection Simulation Exercises. Proceedings of the AHFE 2016 International Conference on Ergonomics Modeling pp 245-254.

[14] Womack, J. P., Jones, D. T. (2003). Lean Thinking: Banish Waste and Create Wealth in your Corporation. Free Press, New York. 